\title{
Construção e validação preliminar do instrumento de avaliação do desempenho técnico-tático no futsal
}

http://dx.doi.org/10.11606/1807-5509201900040597

\author{
Michél Angillo SAAD* \\ Carine COLLET" \\ Juarez Vieira do NASCIMENTO"
}

'Departamento de Educação Física, Universidade Federal de Santa Catarina, Florianópolis, SC, Brasil.

\section{Resumo}

A avaliação do desempenho tem sido um procedimento fundamental para identificar as qualidades, as carências e o progresso dos jogadores, bem como no planejamento e controle do processo de treinamento, seja na fase de formação ou em equipes no alto rendimento. 0 objetivo deste estudo foi construir e validar preliminarmente o Instrumento de Avaliação do Desempenho Técnico-Tático no Futsal (IAD-Futsal), por meio da validação de conteúdo e da verificação da fidedignidade intra e interavaliadores. Para tanto, foram avaliadas as dimensões de adaptação, tomada de decisão e eficácia das ações técnico-táticas realizadas pelos jogadores de futsal. Os dados para a testagem do instrumento foram coletados em 2 jogos de uma equipe masculina da categoria sub-13 e de uma sub-15, totalizando 18 atletas e analisados estatisticamente no programa SPSS for Windows, determinando índices de aceitação para cada ação específica de jogo e cada componente do desempenho. De maneira geral, o instrumento obteve altos índices de validade $(0,86$ e 0,87) e de fidedignidade intra $(0,85)$ e interavaliadores $(0,73$ a 0,82). As evidências indicam que Instrumento de Avaliação do Desempenho Técnico-Tático no Futsal compreende uma ferramenta de observação consistente, possibilitando, de forma fidedigna e confiável, a avaliação e determinação do nível do desempenho esportivo geral e específico de jogadores das categorias de formação no futsal.

Palavras-Chave: Esporte; Validação; Desempenho; Avaliação.

\section{Introdução}

A obtenção de informações a respeito do nível de desempenho dos jogadores tem sido um procedimento importante no processo de desenvolvimento esportivo. Além de auxiliar nos direcionamentos e procedimentos a serem adotados pelos treinadores, seja em um plano mais geral de trabalho ou mesmo na condução das sessões diárias de treinamento, a avaliação do desempenho esportivo tem se consolidado como um ponto de investigação importante no planejamento, execução e controle de treinamento ${ }^{1-5}$.

As mudanças conceituais e metodológicas notadas na área da formação esportiva destacam a importância de desenvolvimento conjunto da técnica e da tática com enfoque no pensamento crítico e reflexivo ${ }^{6,7}$, bem como visando contemplar o conceito de multidimensionalidade técnica ${ }^{8,9}$. Sob o ponto de vista da formação de jovens esportistas, a evolução das metodologias de ensino tem apontado para a necessidade do desenvolvimento conjunto dos aspectos técnicos e táticos do jogo durante os treinamentos, sugerindo que os enfoques dos instrumentos de avaliação dos atletas e de análise do jogo acompanhem essa evolução ${ }^{6}$. Ademais, verifica-se a necessidade da criação de instrumentos de simples aplicação e fácil acesso aos profissionais que atuam no ensino dos esportes.

O Futsal, assim como os demais esportes coletivos de invasão, é um esporte com características predominantemente abertas, onde suas capacidades técnicas e táticas implicam na necessidade de se adaptar às ações motoras de diferentes elementos presentes no jogo, como os colegas e adversários ${ }^{10}$. Tais características conferem a essas modalidades 
necessidades específicas no que diz respeito à condução do processo de ensino-aprendizagemtreinamento, bem como da avaliação do desempenho dos jogadores.

$\mathrm{Na}$ literatura consultada, os instrumentos frequentemente empregados na avaliação dos jogadores são o GPAI (Game Performance Assessment Instrument ${ }^{2}$ ) e o TSAP (Team Sport Assessment Procedure $^{I}$ ), os quais permitem avaliar o desempenho nos esportes coletivos de maneira geral, porém sem abordar as particularidades de cada modalidade. Outro instrumento desenvolvido para a avaliação no futebol é o FUT-SAT ${ }^{5}$, que avalia o desempenho dos jogadores em situações de jogo reduzidas (goleiro + 3 jogadores vs. 3 jogadores + goleiro).

Um aspecto a destacar é o uso frequente de instrumentos de avaliação individuais ${ }^{11-14}$ e a preocupação de contemplar também as ações táticas ${ }^{15-17}$. Entretanto, poucos instrumentos oferecem subsídios para a avaliação de todos os

\section{Método}

\section{Construção do Instrumento}

Os indicadores e os componentes de observação foram determinados a partir da realização de um estudo de revisão sistemática ${ }^{7}$, que teve por objetivo identificar e conhecer os instrumentos de avaliação do desempenho existentes. A revisão sistemática concentrou-se na análise de 12 estudos que abordavam a construção e validação de instrumentos de avaliação técnico-tática nas modalidades coletivas, bem como de outros 17 estudos que reproduziram e/ou adaptaram tais instrumentos em situações de jogo.

O instrumento foi construído a partir da estrutura conceitual e formato dos instrumentos $\mathrm{GPAI}^{2}$, TSAP $^{1}$ e FUT-SAT ${ }^{5}$, bem como do Instrumento de Avaliação do Desempenho Técnico-Tático do Voleibol (IAD-VB ${ }^{18}$ ) e do Instrumento de Avaliação do Desempenho Técnico-Tático Individual nas Categorias de Formação do Basquetebol (IAD$\mathrm{BB}^{19}$ ). Para utilização no futsal, foram adaptados os indicadores de avaliação, visando contemplar as peculiaridades do jogo, as quais referem-se, principalmente, às movimentaçôes que são realizadas de maneira mais encadeada entre ataque e defesa e com maiores interferências contextuais, tendo em vista que a dimensão da quadra e o componentes do desempenho. Na maioria das vezes, a avaliação é centrada somente na eficácia das ações em jogo, por meio da utilização de sistemas de observação direta ou "scout", reduzindo o desempenho apenas ao resultado da ação realizada.

A construção de um novo instrumento de avaliação do desempenho é necessária para viabilizar a aplicação em situações reais de jogo de futsal na situação $5 \times 5$, considerando a presença e a qualidade da interação com o adversário e a análise conjunta dos diversos elementos presentes no jogo. Neste sentido, a realização deste estudo teve por objetivo construir e validar de forma preliminar um instrumento de avaliação técnico-tático no futsal em ambiente de jogo de jogadores de futsal nas categorias de formação. Para tanto, foi necessário determinar os componentes do desempenho e os indicadores de observação, validar o conteúdo e verificar a fidedignidade intra e interavaliadores na aplicação do instrumento.

número de jogadores são reduzidos em relação ao futebol. Tais fatores conferem ao futsal maior dinamicidade das açôes e, consequentemente, maior interação entre os jogadores.

Desta forma, o instrumento elaborado para a modalidade futsal apresenta como indicadores de observação as ações realizadas, considerando os princípios gerais do jogo de futsal na relação entre as açôes de ataque e defesa ${ }^{20}$. Assim, na fase de ataque é avaliado o jogador com a posse de bola, por meio das ações de condução, passe, recepção, drible e finalização, bem como o jogador sem a posse de bola, pela ação desmarcação. $\mathrm{Na}$ fase de defesa, avalia-se, também, o jogador que protege a sua meta da progressão ou finalização do jogador adversário com a posse da bola, pela ação de marcação ao jogador com a posse da bola e, ainda, protege a sua meta do avanço do atacante que busca espaço na quadra de defesa, por meio da ação marcação ao jogador sem a posse da bola.

Os componentes do desempenho a serem avaliados compreendem: a adaptação, a tomada de decisão e a eficácia. A escolha desses componentes é justificada pela complexidade do jogo, bem como pela importância de tais componentes para o desempenho técnico-tático. Enquanto que a adaptação corresponde aos comportamentos que 
precedem ou sucedem o contato direto com a bola em termos de local, postura e velocidade/ sincronização/antecipação do jogador sem bola, a tomada de decisão diz respeito ao conjunto de processos de seleção e escolha de uma determinada ação com o intuito de resolver a situação problema com a qual o jogador se defronta. A eficácia está relacionada com o resultado da ação, ou seja, o resultado obtido em decorrência da execução das habilidades fundamentais do jogo, em função de erro individual, erro provocado pelo adversário ou êxito individual. Os indicadores de observação de cada ação técnico-tática dos jogadores são descritos para avaliação de maneira individual, mas inseridos em situaçôes contextuais de ataque e defesa, e estão relacionados aos componentes de adaptação, tomada de decisão e eficácia.

A utilização do instrumento se baseia na observação de filmagens de jogos de futsal, a fim de analisar o desempenho técnico-tático individual inserido nas situações de jogo propriamente dito $(5 \times 5)$, no qual estejam presentes todas as variáveis que influenciam o rendimento esportivo. A filmagem deve ser realizada por meio da colocação da câmera em um ponto alto que possibilite a visão da quadra por inteiro, podendo ser atrás e para cima do corner ou atrás e acima das goleiras. Posteriormente, a aplicação do instrumento deverá seguir a ordem de açôes realizadas pelo jogador analisado, realizando as avaliações de acordo com os indicadores estabelecidos no instrumento.

A grelha de registro das informações deverá contemplar: o número do jogador, o tempo e a fase de jogo em que cada ação acontece, a ação específica realizada e a atribuição de pontuação para cada componente de desempenho (adaptação, tomada de decisão e eficácia). Após a obtenção das pontuações de cada indicador utiliza-se equaçôes para determinar do nível de desempenho específico por ação, por componente e geral do jogador.

\section{Processo de validação de conteúdo do instrumento}

O processo de validação de conteúdo foi realizado por 15 especialistas da área, todos com formação acadêmica em Educação Física e que atuam como treinadores e/ou na formação de jovens praticantes de futsal, considerados conhecedores do treinamento do futsal e com experiência profissional na área específica deste estudo há, no mínimo, 10 anos, de acordo com as indicações da literatura ${ }^{21}$. A validação de conteúdo concentrouse em indicadores nas dimensóes da clareza de linguagem (linguagem utilizada para determinar cada indicador); pertinência prática (importância do que o indicador se propõe a avaliar); e relevância teórica (nível de associação entre o indicador e a teoria) $)^{22}$. Ao analisar o instrumento, cada avaliador deveria atribuir um valor numérico para determinar o nível de adequação de cada indicador (escala Likert de 1 a 5).

\section{Testagem do instrumento}

Após a validação do conteúdo, realizou-se a testagem do instrumento por meio da verificação $\mathrm{da}$ fidedignidade interavaliadores e intra-avaliador ${ }^{23}$. Para tanto, foram realizadas avaliaçōes de 5 situações de cada ação técnico-tática, tanto da fase de ataque quanto da fase de defesa, totalizando 90 ações analisadas. As ações foram realizadas por um total de 18 atletas e coletadas em 2 jogos de futsal de uma equipe masculina da categoria sub-13 e de uma equipe da categoria sub-15, a fim de assegurar que os indicadores de avaliação fossem representativos das ações observadas em categorias distintas do futsal. A escolha das equipes foi intencional, tendo em vista a participação no campeonato estadual, pela sua tradição na formação de jogadores, assim como pela acessibilidade e permissão de captura de imagens pelo dirigente do clube. Foram tomados todos os cuidados éticos para a captura das imagens, nomeadamente pela aprovação do projeto pelo CEPSH/UFSC (Parecer n. 125/08), bem como com a assinatura do Termo de Consentimento Livre e Esclarecido (TCLE) por parte dos pais/responsáveis e treinadores das equipes.

A testagem interavaliadores do instrumento foi realizada, de forma individual e sem interferência, por cinco pesquisadores treinados que, por meio da observação em vídeo, aplicaram o instrumento para avaliar os jogadores participantes dos jogos selecionados. Os avaliadores assistiram cada vídeo uma vez, sendo que puderam voltar e pausar o vídeo nas ações que tivessem dúvidas na avaliação. Ao final das avaliações, foram comparados os dados dos cinco avaliadores e realizados os cálculos para a definição da concordância entre eles.

A fidedignidade intra-avaliador foi realizada pelo método teste-reteste, por um dos pesquisadores treinados, que reavaliou os mesmos jogos duas semanas após a avaliação inicial. Os dados da primeira e da segunda avaliação foram computados 
e comparados a fim de determinar a estabilidade do instrumento, por meio do índice de correlação intra-avaliador.

\section{Análise dos dados}

No cálculo do coeficiente de validade de conteúdo (CVC) foram consideradas as médias de aceitação específica e geral das ações, componentes e indicadores do instrumento. Os indicadores foram considerados válidos quando apresentaram índices superiores ou iguais a $0,80^{22}$. Enquanto que os índices de correlação de Spearman (intra-avaliador) e intraclasse (interavaliadores) foram classificados em correlação fraca $(0,20$ a 0,40$)$, moderada $(0,41$ a 0,60$)$ e forte (valores acima de 0,61$)^{24}$, os índices de concordância Kappa(intra-avaliador) foram classificados em concordância ruim (valores inferiores a 0,20$)$, fraca $(0,21$ a 0,40$)$, moderada $(0,41$ a 0,60$)$, boa $(0,61$ a 0,80$)$ e excelente $(0,81$ a 1,0$)^{25}$.

Os dados referentes à validação de conteúdo, fidedignidade interavaliadores e intra-avaliador foram organizados na planilha de cálculo Excel, do sistema operacional Windows e analisados estatisticamente no programa Statistical Package for the Social Science (SPSS) for Windows, versão 16.0. O nível de significância utilizado foi de 5\%.

\section{Resultados}

Instrumento de Avaliação do Desempenho Técnico-Tático no Futsal

O Instrumento de Avaliação do Desempenho Técnico-Tático no Futsal (IAD-Futsal) busca analisar as ações técnico-táticas por meio de três componentes do desempenho esportivo, relacionados com a adaptação, a tomada de decisão e a eficácia, sendo que cada um deles apresenta três indicadores de avaliação. Além disso, o instrumento é dividido em fase de defesa (QUADRO 1) e fase de ataque (QUADRO 2), visando facilitar a descrição dos indicadores em cada momento. $\mathrm{O}$ instrumento pode ser utilizado também de forma adaptada, obtendo informaçōes acerca do desempenho específico por ação (desempenho nas finalizações, por exemplo) e também do desempenho específico por componente (nível de desempenho na tomada de decisão do jogador, por exemplo).

QUADRO 1 - Indicadores de observação do Instrumento de Avaliação do Desempenho Técnico-Tático no Futsal em relação à fase de defesa.

Fonte: elaborado pelos autores.

\begin{tabular}{|c|c|c|}
\hline \multicolumn{3}{|r|}{ Fase de Defesa } \\
\hline Açáo & Componente & Indicadores \\
\hline $\begin{array}{l}\text { Marcação ao adversário } \\
\text { com a posse da bola }\end{array}$ & \multirow{2}{*}{ Adaptação } & $\begin{array}{l}\text { AMcb 1: Posiciona-se a uma distância entre o atacante e a meta a defen- } \\
\text { der que lhe possibilite permanecer marcando o adversário (em funçáo da } \\
\text { distância do adversário à meta). } \\
\text { AMcb 2: Estar em equilíbrio conforme a posição básica de marcação. } \\
\text { AMcb 3: Adapta-se à velocidade imposta pelo adversário - que possibilite } \\
\text { permanecer marcando. }\end{array}$ \\
\hline $\begin{array}{l}\text { Marcação ao adversário } \\
\text { sem a posse da bola }\end{array}$ & & $\begin{array}{l}\text { AMsb1: Coloca-se num local que dificulte a progressão do adversário el } \\
\text { ou o recebimento da bola. } \\
\text { AMsb 2: Assume posição básica de marcação e posiciona-se de maneira } \\
\text { que assegure ter a visão do adversário e da bola. } \\
\text { AMsb 3: Adapta-se à velocidade imposta pelo adversário. }\end{array}$ \\
\hline $\begin{array}{l}\text { Marcação ao adversário } \\
\text { com a posse da bola }\end{array}$ & Tomada de Decisão & $\begin{array}{l}\text { TDMsb1: Marca o adversário sem oferecer resistência (sem pressioná-lo), } \\
\text { permite sua progressão ou disputa a bola de forma precipitada. } \\
\text { TDMsb2: Impede a progressão ou a finalização do adversário. } \\
\text { TDMsb3: Pressiona o adversário para recuperar a posse de bola ou impe- } \\
\text { dir a sequência da jogada (induz o adversário ao erro). }\end{array}$ \\
\hline
\end{tabular}

continua 
continuação

\begin{tabular}{|c|c|c|}
\hline \multicolumn{3}{|r|}{ Fase de Defesa } \\
\hline Açáo & Componente & Indicadores \\
\hline $\begin{array}{l}\text { Marcação individual ao } \\
\text { adversário sem a posse } \\
\text { da bola }\end{array}$ & Tomada de Decisão & $\begin{array}{l}\text { TDMsb1: Não busca inibir a progressão do adversário e a recepção da } \\
\text { bola (permitindo receber a bola). } \\
\text { TDMsb2: Busca inibir a progressáo do adversário ou a recepção da bola } \\
\text { (marca o adversário na linha do passe). } \\
\text { TDMsb3: Marca o adversário, pressionando-o para que não receba a } \\
\text { bola. }\end{array}$ \\
\hline $\begin{array}{l}\text { Marcação por zona ao } \\
\text { adversário sem a bola }\end{array}$ & & $\begin{array}{l}\text { TDMb1: Marca fora da linha de passe e não realiza cobertura. } \\
\text { TDMb2: Marca somente na linha de passe, sem se preocupar com a } \\
\text { cobertura. } \\
\text { TDMb3: Marca na linha de passe e realiza cobertura aos companheiros. }\end{array}$ \\
\hline $\begin{array}{l}\text { Marcação ao adversário } \\
\text { com a posse da bola }\end{array}$ & Eficácia & $\begin{array}{c}\text { EMb1: Não impede a sequência da ação do jogador adversário } \\
\text { (sequência da ação = realização de drible, condução, passe, finalização). } \\
\text { EMb2: Dificulta a sequência da ação do jogador adversário, mas não } \\
\text { recupera a posse da bola. } \\
\text { EMb3: Recupera a posse da bola. }\end{array}$ \\
\hline $\begin{array}{c}\text { Marcação ao adversário } \\
\text { sem a posse da bola }\end{array}$ & & $\begin{array}{l}\text { EMsb1: Não dificulta que o adversário progrida e/ou receba a bola. } \\
\text { EMsb2: Dificulta que o adversário progrida e/ou receba a bola. } \\
\text { EMsb3: Impede que o adversário progrida e/ou receba a bola. }\end{array}$ \\
\hline
\end{tabular}

QUADRO 2 - Indicadores de observação do Instrumento de Avaliação do Desempenho Técnico-Tático no Futsal em relação à fase de ataque.

\begin{tabular}{|c|c|c|}
\hline \multicolumn{3}{|r|}{ Fase de Ataque } \\
\hline Açáo & Componente & Indicadores \\
\hline Desmarcação & Adaptação & $\begin{array}{l}\text { AD1: Posiciona/ocupa espaço na quadra em condiçóes de receber a bola } \\
\text { (linha de passe). } \\
\text { AD 2: Posiciona/ajusta o corpo para receber a bola. } \\
\text { AD 3: Alterna velocidade e direção para desvencilhar-se do adversário. }\end{array}$ \\
\hline Condução & & $\begin{array}{l}\text { TDC1: Conduz para um espaço onde há marcação (jogador adversário). } \\
\text { TDC2: Conduz para um espaço livre. } \\
\text { TDC3: Conduz para um espaço livre em direção à meta. }\end{array}$ \\
\hline Passe & & $\begin{array}{l}\text { TDP1: Passa para um colega marcado. } \\
\text { TDP2: Passa para um colega livre de marcaçáo. } \\
\text { TDP3: Passa para um colega em condiçóes de avançar e/ou finalizar. }\end{array}$ \\
\hline Finalização & & $\begin{array}{l}\text { TDF1: Finaliza com marcação pressionada pelo adversário e/ou em local } \\
\text { inapropriado. } \\
\text { TDF2: Finaliza com marcação facilitada do adversário. } \\
\text { TDF3: Finaliza livre, em espaço apropriado. }\end{array}$ \\
\hline Drible & Tomada de Decisão & $\begin{array}{l}\text { TDD1: Dribla em local inapropriado, com marcação pressionada e/ou } \\
\text { sem cobertura. } \\
\text { TDD2: Dribla sem objetivo de açáo ofensiva e/ou para manter a posse da } \\
\text { bola. } \\
\text { TDD3: Dribla obtendo espaço na defesa em condições de finalização e/ } \\
\text { ou continuidade de ação ofensiva. }\end{array}$ \\
\hline Desmarcação & & $\begin{array}{l}\text { TDD1: Não se apresenta para receber a bola e/ou não cria linha de passe. } \\
\text { TDD2: Busca espaço livre (cria linha de passe), mas em local inadequado } \\
\text { para a sequência ofensiva. } \\
\text { TDD3: Busca espaço livre (cria linha de passe) em local adequado para a } \\
\text { sequência ofensiva. }\end{array}$ \\
\hline Condução & Eficácia & $\begin{array}{l}\text { EC1: Perde o controle da bola sozinho. } \\
\text { EC2: Perde a bola para o adversário. } \\
\text { EC3: Conduz a bola sob seu controle. }\end{array}$ \\
\hline
\end{tabular}

Fonte: elaborado pelos autores. 
continuação

\begin{tabular}{|c|c|c|}
\hline \multicolumn{3}{|r|}{ Fase de Ataque } \\
\hline Açáo & Componente & Indicadores \\
\hline Passe & & $\begin{array}{l}\text { EP1: Erro de passe. } \\
\text { EP2: O passe é interceptado pelo adversário. } \\
\text { EP3: Passa a bola para um companheiro de equipe. }\end{array}$ \\
\hline Recepção & & $\begin{array}{l}\text { ER1: Não consegue o domínio da bola. } \\
\text { ER2: Recebe a bola, mas perde a posse para o adversário. } \\
\text { ER3: Recebe a bola e a mantém sob o seu controle. }\end{array}$ \\
\hline Finalização & Eficácia & $\begin{array}{l}\text { EF1: Finalizou, mas a bola foi para fora da área de jogo. } \\
\text { EF2: Finalizou, mas a bola foi interceptada pelo adversário ou defesa do } \\
\text { goleiro. } \\
\text { EF3: Finalizou e obteve êxito (gol). }\end{array}$ \\
\hline Drible & & $\begin{array}{l}\text { ED1: Perdeu a posse da bola. } \\
\text { ED2: Passou pelo adversário com a bola e a manteve sob seu controle. } \\
\text { ED3: Passou pelo adversário com a bola e realizou um passe ou finalizou. }\end{array}$ \\
\hline Desmarcação & & $\begin{array}{l}\text { ED1: Não reagiu à ação da marcação. } \\
\text { ED2: Não consegue se desmarcar. } \\
\text { ED3: Consegue se desmarcar. }\end{array}$ \\
\hline
\end{tabular}

Critérios de Pontuação e Classificaçáo do Nível de Desempenho

Os critérios de pontuação (QUADRO 3 ) de cada indicador foram determinados ao final da construçáo do instrumento, levandose em conta as diferenças de características de cada componente (QUADRO 2). O nível de desempenho técnico-tático dos jogadores corresponde ao somatório de pontos obtidos pelo jogador durante a avaliação sendo as equações determinadas com base na ponderaçáo entre os valores mínimos e máximos que o jogador pode obter em determinada ação de jogo.

Com a aplicação do instrumento podem ser estabelecidos os níveis de Desempenho Específico por Ação (DEA), o nível de Desempenho
Específico por Componente (DEC) e o nível de Desempenho Geral (DEG) do jogador, que é determinado pelo cálculo da média ponderada do desempenho específico nos três componentes. As equações do desempenho por ação foram determinadas de acordo com o número de componentes a que cada ação corresponde (1 componente, 2 componentes, 3 componentes), uma vez que não são todas as açôes de jogo que fazem parte dos três componentes do instrumento (QUADRO 4).

As equações de cálculo do DEA e do DEC são adaptadas do Instrumento de Avaliação do Desempenho Técnico-Tático no Voleibol ${ }^{18} \mathrm{e}$ do instrumento de avaliação do desempenho técnico-tático individual nas categorias de formação do basquetebol ${ }^{19}$.

QUADRO 3 - Critérios de pontuação estabelecidos para o Instrumento de Avaliação do Desempenho TécnicoTático no Futsal.

\begin{tabular}{|c|c|c|}
\hline Componente & Característica & Critérios de pontuação \\
\hline Adaptação & Complementaridade & $\begin{array}{l}1 \text { ponto: realiza nenhum ou somente } 1 \text { dos itens. } \\
2 \text { pontos: realiza } 2 \text { itens. } \\
3 \text { pontos: realiza } 3 \text { itens. }\end{array}$ \\
\hline Tomada de Decisáo & Contraposição & $\begin{array}{l}1 \text { ponto: decisão pouco apropriada. } \\
2 \text { pontos: decisáo apropriada. } \\
3 \text { pontos: decisão altamente apropriada. }\end{array}$ \\
\hline Eficácia & Contraposição & $\begin{array}{l}1 \text { ponto: ação ineficaz do jogador. } \\
2 \text { pontos: ação razoavelmente eficaz do jogador. } \\
3 \text { pontos: ação altamente eficaz do jogador. }\end{array}$ \\
\hline
\end{tabular}


QUADRO 4 - Equações para cálculo do DEA, DEC e DEG.

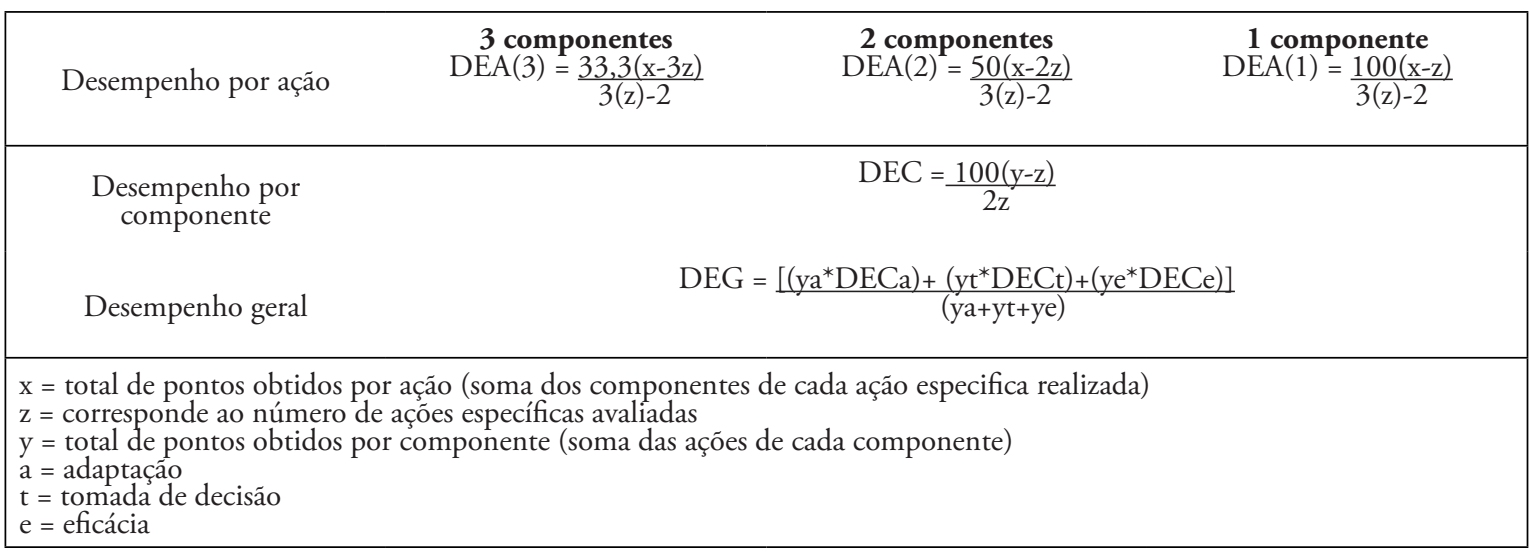

\section{Processo de Validação de Conteúdo}

A validação de conteúdo apresentou elevados índices gerais de clareza de linguagem $(0,86)$ e de pertinência prática $(0,87)$, tornando o instrumento adequado ao que se propóe. Ao observar os dados de cada item, constatou-se que todos obtiveram índices acima de 0,80, sendo considerados satisfatórios (TABELA 1).
Enquanto que os maiores índices do CVC foram obtidos nos componentes eficácia do comportamento dos jogadores com a bola e sem a bola, os menores índices foram nos componentes adaptação e tomada de decisão nos comportamentos sem a bola. De modo geral, os indicadores dos componentes no comportamento dos jogadores com a bola apresentaram índices superiores aos indicadores dos componentes nos comportamentos sem a bola.

TABELA 1 - Coeficientes de Validade de Conteúdo (CVC) por componentes e indicadores.

\begin{tabular}{|c|c|c|}
\hline Componentes e indicadores & Clareza de Linguagem & Relevância Prática \\
\hline \multicolumn{3}{|l|}{ Adaptaçáo } \\
\hline Marcação ao jogador sem a bola & 0,83 & 0,82 \\
\hline Marcação ao jogador com a bola & 0,84 & 0,84 \\
\hline Desmarcação & 0,80 & 0,80 \\
\hline \multicolumn{3}{|l|}{ Eficácia - movimentos sem a bola } \\
\hline Marcação ao jogador sem a bola & 0,92 & 0,86 \\
\hline Marcação ao jogador com a bola & 0,91 & 0,88 \\
\hline Desmarcação & 0,86 & 0,82 \\
\hline \multicolumn{3}{|l|}{ Eficácia - movimentos com a bola } \\
\hline Condução & 0,93 & 0,90 \\
\hline Passe & 0,90 & 0,91 \\
\hline Recepção & 0,93 & 0,92 \\
\hline Finalização & 0,89 & 0,92 \\
\hline Drible & 0,88 & 0,87 \\
\hline \multicolumn{3}{|c|}{ Tomada de decisáo - movimentos sem a bola } \\
\hline Marcação ao jogador sem a bola & 0,83 & 0,82 \\
\hline Marcaçáo ao jogador com a bola & 0,82 & 0,82 \\
\hline Desmarcação & 0,81 & 0,80 \\
\hline \multicolumn{3}{|c|}{ Tomada de decisáo - movimentos com a bola } \\
\hline Condução & 0,84 & 0,89 \\
\hline Passe & 0,86 & 0,87 \\
\hline Finalização & 0,84 & 0,90 \\
\hline Drible & 0,85 & 0,91 \\
\hline
\end{tabular}




\section{Fidedignidade Intra-avaliador}

Para obtenção do grau de fidedignidade intraavaliador foram realizadas 90 avaliaçóes, sendo 5 situaçóes de cada ação de jogo (indicadores), envolvendo os componentes de cada açáo ( 2 ou 3 componentes, conforme a ação avaliada). Desse total, 78 avaliaçóes foram iguais $(86,6 \%)$ e 12 diferentes $(13,4 \%)$, principalmente no que diz respeito aos indicadores marcação e desmarcação, ambas as açóes sem a bola, nos componentes eficácia e tomada de decisão.

O instrumento obteve, conforme os dados da TABELA 2, 86,6\% de concordância bruta, com índice Kappa de 0,82 e coeficiente de correlação de 0,85 , ambos considerados excelentes ${ }^{25}$. Todas as açóes nos componentes eficácia e tomada de decisão obtiveram avaliaçóes iguais, quando comparados o teste e o reteste, obtendo índices de correlação iguais a 1 . As açôes de jogo de marcação ao jogador sem a posse da bola (fase de defesa) e desmarcação (fase de ataque) foram as que apresentaram menor índice de correlação de Spearman $(0,71$ e 0,70, respectivamente) e de concordância Kappa (0,66 e 0,68 , respectivamente), embora estejam no nível considerado como forte correlação ${ }^{24}$. Assim, os indicadores com menores índices de correlação foram revistos e sua descrição foi melhorada a fim de torna-la mais clara.

TABELA 2 - Percentual das avaliações do especialista por componente.

Fonte: elaborado pelos autores a partir da avaliação dos especialistas.

\begin{tabular}{|c|c|c|c|c|c|c|}
\hline \multirow{2}{*}{ Indicadores } & \multicolumn{3}{|c|}{ Componentes } & \multirow{2}{*}{ Total } & \multirow{2}{*}{ Spearman } & \multirow{2}{*}{ Kappa } \\
\hline & Adaptaçáo & Eficácia & $\begin{array}{c}\text { Tomada de } \\
\text { Decisáo }\end{array}$ & & & \\
\hline $\begin{array}{l}\text { Marcação ao jogador } \\
\text { com a bola }\end{array}$ & $80 \%$ & $80 \%$ & $60 \%$ & $73,3 \%$ & 0,73 & 0,75 \\
\hline $\begin{array}{l}\text { Marcação ao jogador } \\
\text { sem a bola }\end{array}$ & $80 \%$ & $80 \%$ & $60 \%$ & $73,3 \%$ & 0,71 & 0,68 \\
\hline Desmarcação & $80 \%$ & $60 \%$ & $80 \%$ & $73,3 \%$ & 0,70 & 0,66 \\
\hline Conduçãoo & - & $100 \%$ & $100 \%$ & $100 \%$ & 1 & 1 \\
\hline Passe & - & $100 \%$ & $100 \%$ & $100 \%$ & 1 & 1 \\
\hline Finalização & - & $100 \%$ & $100 \%$ & $100 \%$ & 1 & 1 \\
\hline Drible & - & $100 \%$ & $100 \%$ & $100 \%$ & 1 & 1 \\
\hline Recepção & - & $100 \%$ & - & $100 \%$ & 1 & 1 \\
\hline Total & $80 \%$ & $90 \%$ & $85,7 \%$ & $86,6 \%$ & & \\
\hline Spearman & 0,72 & 0,78 & 0,73 & 0,85 & - & - \\
\hline Kappa & 0,71 & 0,73 & 0,72 & 0,82 & - & - \\
\hline
\end{tabular}

\section{Fidedignidade Interavaliadores}

Os dados da TABELA 3 mostram os índices de correlação intraclasse, comparando as análises dos 5 avaliadores. Todos os coeficientes de correlação foram considerados fortes, pois variaram de 0,73 a 0,82 . O maior coeficiente de correlação foi observado entre os avaliadores 2 e 5 , os quais apresentaram critérios semelhantes na aplicação do instrumento.

Os demais índices foram considerados satisfatórios, revelando que o instrumento possui graus elevados de correlação entre os diferentes avaliadores. O coeficiente mais baixo foi observado entre os avaliadores 3 e 5 , pois algumas avaliaçóes, em relação aos componentes adaptação e tomada de decisão, foram distintas entre ambos. 
TABELA 3 - Índices de correlação geral entre os avaliadores.

\begin{tabular}{cccccc}
\hline Avaliadores & $\mathbf{1}$ & $\mathbf{2}$ & $\mathbf{3}$ & $\mathbf{4}$ & $\mathbf{5}$ \\
\hline $\mathbf{1}$ & & & & & \\
$\mathbf{2}$ & $0,76^{*}$ & & & \\
$\mathbf{3}$ & $0,81^{*}$ & $0,77^{*}$ & & \\
$\mathbf{4}$ & $0,74^{*}$ & $0,75^{*}$ & $0,77^{*}$ & & \\
$\mathbf{5}$ & $0,77^{*}$ & $0,82^{*}$ & $0,73^{*}$ & $0,80^{*}$ & \\
\hline
\end{tabular}

\section{Discussão}

Os instrumentos de avaliação do desempenho técnico-tático têm, usualmente, limitaçôes em analisar um único indivíduo na complexidade do jogo, como é o caso do futsal. Nas últimas três décadas, uma das soluçôes encontradas é a utilizaçáo de sistemas de coleta e análise de dados por treinadores ou investigadores de ciências do esporte $^{1,2,5,18,19}$. O apelo ao ensino da dimensão tática nos esportes coletivos implica igualmente, na adoção de instrumentos que possam avaliar a capacidade de decisão e de resoluçáo dos problemas que surgem nas situaçóes reais e cotidianas de prática esportiva.

No instrumento de avaliação construído, para cada componente a ser avaliado, foram elencados indicadores de observação, considerando as açôes técnico-táticas dos jogadores nas situações de defesa e ataque, com e sem a posse da bola. A perspectiva de análise se dá a partir da estrutura funcional dos esportes de equipe, na qual as açôes se desenvolvem em um espaço comum, com participação simultânea de defensores e atacantes em relação à bola, determinando-se os indicadores de observação ${ }^{26,27}$.

A construção do instrumento possui a estrutura dividida em duas partes, uma relacionada à fase de defesa a outra à fase de ataque, considerando os princípios gerais do jogo na relação entre as duas fases $^{20}$. As ações técnico-táticas da defesa (marcação do adversário com e sem a bola, marcação individual do adversário com a bola e marcação por zona ao adversário sem a bola) são avaliadas quando o jogador tem por objetivo a recuperação da bola, impedir a progressão do jogador atacante e da bola e a proteção da sua meta ou espaço na quadra de jogo. Em contrapartida, as açōes técnico-táticas do ataque (desmarcação, condução, passe, drible, recepção e finalização) são caracterizadas pela posse da bola, na perspectiva de conservação, a progressão em direção à meta adversária e a finalização no intuito de atingir o gol.

Os indicadores de observação contemplam as fases de preparação para a realização das ações, por meio do componente denominado "adaptação", as possibilidades de decisão em cada ação, pelo componente "tomada de decisão", e os resultados obtidos por meio da execução das habilidades fundamentais do jogo, por meio da "eficácia"28,29.

$O$ processo de validação do IAD-Futsal, realizado com a participação de experts na modalidade de diversas regióes do Brasil, tanto no âmbito da investigação acadêmica quanto na intervenção direta no treinamento com as categorias de formação, revelou índices de validade acima de 0,80 , de maneira geral e em cada ação específica. Destacase que a maioria dos indicadores do instrumento obteve altos índices de validade na dimensão da relevância teórica, revelando que os indicadores corresponderam adequadamente aos elementos contemplados na literatura da área $a^{1,2,530,31}$.

Os índices de validade e fidedignidade observados no estudo apresentaram maiores valores no componente eficácia, devido à facilidade em identificar e visualizar o resultado da ação executada pelos jogadores. Por outro lado, os menores índices são relacionados ao componente da adaptação que, devido as suas características cognitivas, requer uma avaliação mais subjetiva que objetiva. Tal fato pode ser explicado pela maior dificuldade em avaliar estes componentes por meio da percepção na ação, ou seja, a principal dificuldade em avaliar a tomada de decisão está em identificar como os processos cognitivos se expressam no comportamento, ao longo da realização de tarefas esportivas ${ }^{32}$. Embora proporcione oportunidades à algumas diferentes interpretações, as avaliações não afetaram a validade dos indicadores.

A avaliação dos especialistas acerca dos indicadores de cada ação, de maneira geral, demonstrou índices 
altamente válidos ${ }^{22,24,25}$, considerando que os elementos utilizados para a descrição e a definição dos indicadores eram possíveis de observação durante as situaçôes de jogo. Na fidedignidade interavaliadores, os índices menos expressivos foram encontrados no componente adaptação, em virtude da maior dificuldade de leitura do contexto de jogo e da interpretação do local ideal em que deveria estar cada jogador, o que consiste em uma limitação inerente ao sistema de observação. Cabe destacar que esse componente abrange particularidades estratégicas e, na maioria das vezes, os jogadores posicionam-se ou deslocam-se em razão do sistema de jogo adotado pelo treinador.

Apesar da escolha de três categorias do nível de desempenho dos atletas constituir um fator limitante na determinação da estabilidade e da objetividade do instrumento, a escolha dessas categorias facilita a aplicação do IAD-Futsal por pesquisadores e treinadores. Em contrapartida, os instrumentos de observação nessa área geralmente apresentam apenas dois níveis de desempenho (escala dicotômica), o que tem proporcionado uma interpretação do comportamento pouco específica, assim como tem dificultado a obtenção de medidas que descrevam com maior precisão aos comportamentos e intençóes dos jogadores.

Com relação à fidedignidade intra-avaliador, encontrou-se índice elevado de avaliações iguais $(86,6 \%)$, principalmente no que se refere às ações de ataque com a posse da bola, indicando maior facilidade em avaliar os aspectos ofensivos dos jogadores. Apesar dos menores índices observados nas ações de defesa (marcação aos jogadores sem a posse da bola), os resultados confirmam que o instrumento é fidedigno e constitui importante ferramenta na determinação do nível de desempenho dos jogadores. Valores similares de fidedignidade intra-avaliador também foram encontrados em outros instrumentos desenvolvidos para avaliar o desempenho de atletas de modalidades esportivas coletivas $^{18,19,31}$.

$\mathrm{Na}$ avaliação da fidedignidade interavaliadores, as diferenças encontradas estavam relacionadas com a interpretação das situações e contextos apresentados no jogo. Em muitos casos, tais interpretações dependem do nível de envolvimento do observador com a modalidade esportiva, pois alguns pormenores são mais facilmente identificados por quem já possui conhecimento mais aprofundado da modalidade. Entretanto, a descrição dos indicadores do instrumento, bem como a validade do seu conteúdo (clareza de linguagem, pertinência prática e relevância teórica) ${ }^{22}$, estabelecida pelos experts na área, possibilita a utilização do instrumento também por pesquisadores e treinadores que não tenham experiência em larga escala com o futsal.

O componente da dimensão técnica (eficácia), por apresentar elementos mais facilmente observáveis, que se relacionam com os resultados de cada ação, obteve maiores índices de validade e fidedignidade intra e interavaliadores. Os componentes da dimensão tática (adaptação e tomada de decisão) apresentaram índices menores, devido à característica cognitiva e adaptativa ao contexto do jogo, tornando a avaliação um pouco mais subjetiva, porém não invalida os indicadores de avaliação do desempenho dos jogadores. Para viabilizar a aplicação do instrumento, todos os indicadores que obtiveram diferenças de avaliações foram revisados e, em alguns casos, modificados, buscando aumentar a objetividade nas observações.

Estudos realizados a partir da utilização de instrumentos de avaliação similares, os quais possuem estrutura conceitual semelhante ao do presente instrumento, revelaram importantes informaçōes acerca do desempenho técnico-tático de jogadores de voleibol de diferentes categorias, inclusive relacionando seu nível de desempenho com a experiência esportiva ${ }^{32}$ e com a classificação em campeonatos específicos das categorias de formação $0^{33}$. O estudo de validação preliminar do instrumento para utilização na modalidade basquetebol ${ }^{19}$ também apresentou índices aceitáveis de validação, semelhantes ao do presente estudo, porém levando em consideração as especificidades da modalidade.

Nas modalidades de futebol e futsal, os estudos encontrados limitaram-se a avaliar o desempenho dos jogadores a partir de critérios técnicos ou táticos, geralmente de ações exclusivamente com a bola ou testes que simulam o jogo. O Inventário de Avaliação da Performance Tática (IAPT) ${ }^{34}$, utilizado para avaliar as decisões tomadas pelos jogadores de futebol na execução de cada ação de jogo, ao classificar as ações somente em correta ou incorreta não possibilita a análise dos comportamentos sem a bola (marcação ou apoio). Outro instrumento identificado com o objetivo de avaliar o desempenho técnico-tático dos jogadores de futebol ${ }^{35}$ foi construído e validado com o propósito de avaliar as tomadas de decisão e a execução das habilidades de cada ação observada, com e sem a bola, porém contempla somente a situação de jogo 3X3. Apesar do "FUT-SAT" compreender um importante 
sistema de avaliação da performance dos jogadores nas ações táticas do futebol, com e sem a posse da bola, ele é realizado apenas em situações de jogo reduzido $(3 \times 3)$. O FUT-SAT também foi utilizado no futsal ${ }^{36}$ para comparar os comportamentos táticos de jogadores das categorias sub-13, sub-15, sub-17 e sub-20.

De modo geral, os estudos no futsal centraramse praticamente na avaliação do comportamento tático por meio de testes de parâmetros muitos específicos. Os estudos realizados nas categorias sub-11 e sub- $13^{37}$ e na categoria sub- $9^{38}$ avaliaram o desempenho tático por meio do teste KORA$\mathrm{OO}^{39}$ (Avaliação Orientada através do Conceito dos Peritos) no parâmetro "oferecer-se" e "orientar-se", que traz informações acerca das movimentações dos jogadores em situações simuladas de jogo 3X3. Assim, cabe destacar que o IAD-Futsal apresenta-se como uma alternativa para avaliar o desempenho dos jogadores em relação as capacidades técnicas e táticas, além da avaliação do desempenho geral do jogador nas situaçôes de ataque e defesa, sem posse de bola e com posse de bola.

Após o estabelecimento de indicadores de desempenho e da respectiva testagem, pode-se concluir que, de maneira geral, o IAD-Futsal mostrou-se cientificamente válido e utilizável na sua avaliação preliminar no que diz respeito à validade de conteúdo e fidedignidade intra e interavaliadores, tanto no âmbito da pesquisa quanto nas situações da prática profissional. Na sequência, serão realizados os testes para verificar a estabilidade do instrumento por meio da análise fatorial e de outras análises para a validação completa do instrumento. Por fim, recomenda-se a realização de estudos exploratórios com diferentes categorias de formação e sexos distintos, a fim de determinar o nível de desempenho geral e específico dos jogadores, bem como comparar as performances considerando as funções desempenhadas em quadra.

\title{
Conflito de interesse
}

Os autores do artigo intitulado CONSTRUÇÃO E VALIDAÇÃO PRELIMINAR DO INSTRUMENTO DE AVALIAÇÃO DO DESEMPENHO TÉCNICO-TÁTICO NO FUTSAL (IAD-Futsal), declaram não ter nenhum potencial de conflito de interesse em relação ao presente, submetido à Revista Brasileira de Educação Física e Esporte.

\begin{abstract}
Construction and preliminary validation of the technical-tactical performance assessment instrument in futsal

Performance evaluation has been a key procedure to identify the qualities, needs, and progress of players as well as planning and control of training process, whether at the stage or in teams at the high performance. The aim of this study was to construct and validate the preliminary Technical-Tactical Performance Assessment Instrument in Futsal through the content validation and verification of intra and inter reliability. Therefore, we evaluated the dimensions of adaptation, decision-making, and effectiveness of technical and tactical actions undertaken by futsal players. The data for testing the instrument were collected in 2 games in a men's team under-13 and under-15, totalizing 18 athletes who were statistically analyzed using SPSS for Windows, determining acceptance rate for each specific action game and performance for each component. Overall, the instrument revealed high levels of validity (0.86 and 0.87 ) and intra (0.85) and inter evaluators reliability $(0.73$ to 0.82$)$. The evidence indicates that the Technical-Tactical Performance Assessment Instrument in Futsal comprises a consistent observation tool, enabling trusted and reliable, evaluation, and determination of the general and specific level of sports performance of players in the training categories in futsal.
\end{abstract}

KEYWORDS: Sport; Validation; Performance; Evaluation.

Rev Bras Educ Fís Esporte, (São Paulo) 2019 Out-Dez; 33(4):597-609 • 607 


\section{Referências}

1. Gréhaigne JF, Godbout P, Bouthier D. Performance assessment in team sports. J Teach Phys Educ. 1997;16(4):500516.

2. Oslin JL, Mitchell SA, Griffin LL. The Game Performance Assessment Instrument (GPAI): Development and Preliminary Validation. J Teach Phys Educ. 1998;17(2):231-243.

3. Paulis JC. Observación y Análisis de la acción de juego en fútbol. Revista Digital EFDeportes. 2000;5(22).

4. Blomqvist M, Vänttinen T, Luhtanen P. Assessment of secondary school students' decision-making and game-play ability in soccer. Phys Educ Sport Pedagog. 2005;10(2):107-119.

5. Costa IT, Garganta J, Greco PJ, Mesquita I, Maia J. Sistema de avaliação táctica no Futebol (FUT-SAT): Desenvolvimento e validação preliminar. Motri. 2011;7(1):69-84.

6. Mesquita I, Graça A. Modelos de ensino dos jogos desportivos. In: Tani G, Bento JO, Petersen RDS, organizadores. Pedagogia do Desporto. Rio de Janeiro: Guanabara Koogan; 2006. p. 269-283.

7. Saad MA, Collet C, Vicente LJ, Ramos V, Nascimento JV. Avaliação do desempenho técnico-tático em modalidades esportivas coletivas. In: Nascimento JV, Ramos V, Tavares F, organizadores. Jogos Desportivos: formação e investigação. Florianópolis: UDESC; 2013. p. 267-291.

8. Konzag IA. Formação técnico-tática nos Jogos Desportivos Coletivos. Treino Desportivo. 1991;2(19):27-37.

9. Rink JE. Teaching physical education for learning. San Louis: Mosby; 1993.

10. Saad MA. A formação técnico-tática de jogadores de futsal nas categorias sub-13 e sub-15: análise do processo de ensino-aprendizagem-treinamento [tese]. Florianópolis (SC): Universidade Federal de Santa Catarina, Centro de Desportos; 2012.

11. Barros RML, Bergo FG, Anido R, Cunha SA, Lima Filho EC de, Brenzikofer R, et al. Sistema para anotação de açóes de jogadores de futebol. Rev Bras Cienc Mov. 2002;10(2):07-14.

12. Vendite LL, Moraes AC, Vendite C. Scout no futebol: uma análise estatística. Conexôes. 2003;1(2):183-194.

13. Leitão RA, Guerreiro Jr FC, Zago L, Moraes AC. Análise da incidência de gols por tempo de jogo no campeonato brasileiro de futebol 2001: estudo comparativo entre as primeiras e últimas equipes colocadas da tabela de classificação. Conexóes. 2003;1(2):195-212.

14. Ramos Filho LAO, Alves DM. Análise do Scout individual da Equipe Profissional de Futebol do Londrina Esporte Clube no Campeonato Paranaense de 2003. Treinamento Desportivo. 2006;7(1):62-67.

15. Tavares F, Veleirinho A. Estudo comparativo das açóes ofensivas desenvolvidas em situação de jogo formal e de jogo reduzido numa equipa de basquetebol de iniciados. Movimento. 1999;5(11):57-64.

16. Rose Jr D, Lamas L. Análise de jogo no basquetebol: perfil ofensivo da Seleção Brasileira Masculina. Rev Bras Educ Fís Esporte. 2006;20(3):165-73.

17. Ferreira RB, Paoli PB, Costa FR. Proposta de “scout” tático para o futebol. Revista Digital EFDeportes. 2008;12(118):1.

18. Collet C, Nascimento JV, Ramos V, Stefanello JMF. Construção e Validação do Instrumento de Avaliação do Desempenho Técnico-Tático no Voleibol. Rev Bras Cineantropom Desempenho Hum. 2011;13(1):43-51.

19. Folle A, Quinaud RT, Barroso MLC, Rocha JCS, Ramos V, Nascimento JV. Construção e validação preliminar de instrumento de avaliação do desempenho técnico-tático individual no basquetebol. Rev Educ Fis. 2014;(25)3:405-418.

20. Bayer C. La enseñanza de los juegos deportivos colectivos. Barcelona: Hispano-Europea; 1986.

21. Balbinotti MA, Benetti C, Terra PRS. Translation and validation of the Graham-Harvey survey for the Brazilian context. Int J Manag Finance. 2006;3:26-48.

22. Cassepp-Borges V, Balbinotti MAA, Teodoro MLM. Tradução e validação de Conteúdo: uma proposta para a adaptação de instrumentos. In: Pasquali L, organizador. Instrumentação Psicológica: fundamentos e práticas. Porto Alegre: Artmed; 2009. p.506-520.

23. O’Donoghue P. Research Methods for Sports Performance analysis. Oxon: Routledge; 2010.

24. Mitra A, Lankford S. Research methods in park, recreation and leisure services. Champaign: Sagamore ;1999.

25. Landis JR, Koch GG. The measurement of observer agreement for categorical data. Biometrics. 1977;33(1):159-174.

26. Hernandez J. Fundamentos del deporte. Análisis de las estructuras del juego deportivo. Barcelona: INDE; 1984.

27. Teodorescu L. Problemas de teoria e metodologia nos jogos desportivos. Lisboa: Livros Horizonte; 1984.

28. Tavares F. Analisar o jogo nos esportes coletivos para melhorar a performance: uma necessidade para o processo de treino. In: Rose Jr D, organizador. Modalidades Esportivas Coletivas. Rio de Janeiro: Guanabara Koogan; 2006. p.6067. 
29. Rink JE, French K, Tjeerdsma L. Foundations for the learning and instruction of sport games. J Teach Phys Educ. 1996;15(4):339-417.

30. Hughes MD, Bartlett RM. The use of performance indicators in performance analysis. J Sports Sci. 2002;20(10):739754.

31. Mesquita I, Graca A, Gomes AR, Cruz C. Examining the impact of a step game approach to teaching volleyball on student tactical decision making and skill execution during game play. J Hum Mov Stud. 2005;48:469-92.

32. Porath M, Nascimento JV, Milistetd M, Collet C, Salles WN, Quinaud RT. Nível de desempenho técnico-tático e experiência esportiva dos atletas de voleibol das categorias de formaçáo. Rev Educ Fís UEM. 2012;23(4):565-574.

33. Porath M, Nascimento JV, Milistetd M, Collet C, Oliveira CC. Nível de desempenho técnico-tático e a classificaçấo final das equipes catarinenses de voleibol das categorias de formaçấo. Rev Bras Educ Fís Esporte. 2016;38(1):84-92.

34. Rezende ALG. Elaboraçáo e estudo de uma metodologia de treinamento voltada para o desenvolvimento das habilidades táticas no futebol de campo com base nos princípios da teoria de formação das açôes mentais por estágios idealizada por Galperin [tese]. Brasília (DF): Universidade de Brasília, Faculdade de Ciências da Saúde; 2003.

35. Tallir I, Musch E, Lannoo K, Voorde J. Validation of video-based instruments for the assessment of game performance in handball and soccer. 2nd International Conference: teaching sport and physical education for understanding; 2003; Melbourne, Australia. Melbourne: University of Melbourne; 2003. p.108-113.

36. Muller E, Garganta J, Santos RMM, Costa IT. Comportamento e desempenho táticos: estudo comparativo entre jogadores de futebol e futsal. Rev Bras Cienc Mov. 2016;24:100-109.

37. Souza PRC. Validação de um teste para avaliar a capacidade de tomada de decisão e o conhecimento declarativo em situaçôes de ataque no futsal [dissertação]. Belo Horizonte (MG): Universidade Federal Minas Gerais, Escola de Educação Física Fisioterapia e Terapia Ocupacional; 2002.

38. Moreira VJP. A influência de processos metodológicos de ensino-aprendizagem-treinamento (E-A-T) na aquisição do conhecimento tático no futsal [dissertaçâo]. Belo Horizonte (MG): Universidade Federal Minas Gerais, Escola de Educaçáo Física Fisioterapia e Terapia Ocupacional; 2005.

39. Memmert D. Diagnostik taktischer leistungskompnenten: Spieltestsituationen und konzeptorientierte expertenratings [tese]. Heidelberg (Alemanha): Universidade de Heidelberg; 2002.

$$
\begin{aligned}
& \text { ENDEREÇO DE CORRESPONDÊNCIA: } \\
& \text { Carine Collet } \\
& \text { Rua Roberto Sampaio Gonzaga, s/n - Trindade } \\
& \text { Florianópolis - SC - BRASIL } \\
& \text { CEP: 88040-900 } \\
& \text { E-mail: ca_collet@hotmail.com }
\end{aligned}
$$

